IRRITABLE BOWEL SYNDROME

\title{
Divergent patterns of total and cancer mortality in ulcerative colitis and Crohn's disease patients: the Florence IBD study 1978-2001
}

\author{
G Masala, S Bagnoli, M Ceroti, C Saieva, G Trallori, I Zanna, G d'Albasio, D Palli
}

Gut 2004;53:1309-1313. doi: 10.1136/gut.2003.031476

See end of article for authors' affiliations

Correspondence to: Dr D Palli, Molecular and Nutritional Epidemiology Unit, CSPO-Scientific Institute of Tuscany, Via di San Salvi 12, 50135 Florence, Italy; d.palli@cspo.it

Accepted for publication 20 January 2004
Background and aims: Two divergent patterns of mortality for smoking related diseases in ulcerative colitis and Crohn's disease patients were suggested in a previous population based study in Florence, Italy. Long term follow up (median 15 years) was completed to re-evaluate mortality in this Mediterranean cohort. Patients and methods: Overall, 920 patients with inflammatory bowel disease were followed until December 2001 or death, with seven patients (0.8\%) lost to follow up. A total of 14040 person years were available for analysis; 118 deaths were observed (81/689 in ulcerative colitis and 37/231 in Crohn's disease). Expected deaths were estimated using age, sex, and calendar specific national and local mortality rates; standardised mortality ratios (SMR) and 95\% confidence interval (CI) were calculated.

Results: Among Crohn's disease patients, mortality was strongly increased for gastrointestinal diseases (SMR 4.49 (95\% Cl 1.80-9.25)), all cancers (SMR 2.10 (95\% Cl 1.22-3.36)), and lung cancer (SMR 4.00 (95\% Cl 1.60-8.24)), leading to a significant 50\% excess total mortality. Ulcerative colitis patients showed a significantly reduced total mortality because of lower cardiovascular (SMR 0.67 (95\% Cl 0.45-0.95)) and lung cancer (SMR 0.32 (95\% Cl 0.07-0.95)) mortality. No significant excess for colorectal cancer mortality was evident in this extended follow up.

Conclusions: These clearly divergent patterns of mortality correlate with documented differences in smoking habits between Crohn's disease and ulcerative colitis patients. Family doctors and gastroenterologists should consider stopping cigarette smoking a specific priority for Crohn's disease patients; the latter should be offered free participation in structured programmes for smoking cessation, with the aim of reducing smoking related excess mortality. Overall, no evidence of an increased mortality for large bowel cancer emerged in this series.
1 nflammatory bowel diseases (IBD), ulcerative colitis (UC) and Crohn's disease (CD), are chronic conditions, with an early onset and a clinical course characterised by alternating remissions and relapses requiring strict medical follow up and long term treatment. ${ }^{1}$ Several studies have been carried out to evaluate general and cause specific mortality in these patients, either in relation to the disease itself or to other causes, particularly cancer. Most studies have reported a reduced or only slightly increased total mortality among UC patients ${ }^{2-10}$; a few Northern European studies, on the other hand, have reported a moderately increased mortality. ${ }^{11-14}$ An excess of general mortality in $\mathrm{CD}$ patients has been reported, ${ }^{212-15}$ with some exceptions. ${ }^{10}{ }^{16} \mathrm{UC}$ patients are considered to be at increased risk for colorectal cancer: mortality from colorectal cancer however has been found to be significantly increased in UC patients in some population based studies ${ }^{12}{ }^{13}$ but not in others. ${ }^{29}$ Other causes of death have also been investigated and it has been found that, overall, IBD patients are at increased risk of death from severe attacks and surgical complications of the disease itself, and from other non-neoplastic gastrointestinal conditions. $^{29121315}$ Increased mortality from respiratory diseases among UC patients has been reported in several studies, ${ }^{6} 9^{1213}$ possibly associated with asthma and pneumonia.

We have previously described an increasing trend in IBD incidence rates in the metropolitan area surrounding Florence over a 15 year period, ${ }^{17}$ and thus we had the opportunity to identify a large population based series of IBD patients. We carried out a study on the mortality experience of this cohort, and a divergent pattern of mortality for smoking related causes (particularly lung cancer) and a non-significant modest increase in colorectal cancer mortality were suggested. ${ }^{2}$ A divergent pattern of lung cancer risk among CD and UC patients has also been suggested in a cancer incidence study recently carried out in the same cohort. ${ }^{18}$

We report here the results of a long term mortality follow up (median 15 years) carried out to re-evaluate the patterns of mortality in this population based cohort, the only one so far available in a Mediterranean country.

\section{METHODS}

A previous population based epidemiological study identified all patients aged at least 15 years with a diagnosis of UC or $\mathrm{CD}$ residing in the metropolitan area of Florence during the period 1978-1992. ${ }^{17}$ Overall, 920 patients with a diagnosis of IBD were followed from enrolment until death or the end of the follow up period (31 December 2001). Four patients had left the country and were censored at the date of migration abroad; three of the 63 patients who migrated elsewhere in Italy could not be traced and were also censored. Overall, therefore, the vital status at the end of follow up was not available for seven $(0.8 \%)$ patients, who were considered for analysis only until the date of migration.

A linkage with local town offices and the Regional Mortality Registry allowed identification of 118 deaths and retrieval of individual death certificates. For only one subject (deceased abroad) was the death certificate not available. Causes of death were classified according to the IXth edition

Abbreviations: $C D$, Crohn's disease; $I B D$, inflammatory bowel disease; SMR, standardised mortality ratio; UC, ulcerative colitis 
Table 1 General and cause specific mortality in the follow up of a population based cohort of 689 ulcerative colitis patients (10 489 person years) by major groups of diagnostic categories (Florence IBD study 1978-2001)

\begin{tabular}{|c|c|c|c|c|c|}
\hline \multirow[b]{2}{*}{ Cause of death } & \multirow[b]{2}{*}{ ICD IX } & \multicolumn{2}{|l|}{ Deaths } & \multirow[b]{2}{*}{ SMR } & \multirow[b]{2}{*}{$95 \% \mathrm{Cl}$} \\
\hline & & $\begin{array}{l}\text { Observed } \\
\text { (n) }\end{array}$ & $\begin{array}{l}\text { Expected } \\
\text { (n) }\end{array}$ & & \\
\hline Neoplasms & $140-208$ & 26 & 36.50 & 0.71 & $(0.47-1.04)$ \\
\hline Digestive system & $150-159$ & 11 & 12.74 & 0.86 & $(0.43-1.55)$ \\
\hline Stomach & 151 & 2 & 3.31 & 0.60 & $(0.07-2.18)$ \\
\hline Colon-rectum & $153-154$ & 4 & 3.16 & 1.26 & $(0.34-3.24)$ \\
\hline Liver & 155 & 2 & 1.90 & 1.05 & $(0.12-3.80)$ \\
\hline Respiratory system & $160-165$ & 3 & 10.43 & $0.29^{*}$ & $(0.06-0.84)$ \\
\hline Lung & 162 & 3 & 9.25 & $0.32^{*}$ & $(0.07-0.95)$ \\
\hline Breast & 174 & 2 & 1.98 & 1.01 & $(0.11-3.65)$ \\
\hline Haematopoietic system & $200-208$ & 4 & 2.54 & 1.57 & $(0.42-4.03)$ \\
\hline Non-Hodgkin's lymphoma & 200-202 & 2 & 0.83 & 2.41 & $(0.27-8.70)$ \\
\hline Other neoplasmst & & 6 & 8.81 & 0.68 & $(0.25-1.48)$ \\
\hline Diabetes & 250 & 2 & 3.58 & 0.56 & $(0.06-2.02)$ \\
\hline Cardiovascular diseases & $390-459$ & 31 & 46.32 & $0.67^{*}$ & $(0.45-0.95)$ \\
\hline Gastrointestinal diseases & $520-579$ & 11 & 7.01 & 1.57 & $(0.78-2.81)$ \\
\hline Violent causes & $800-998$ & 5 & 6.09 & 0.82 & $(0.26-1.92)$ \\
\hline Other causes $\ddagger$ & & 6 & 15.49 & $0.39^{*}$ & $(0.14-0.84)$ \\
\hline All deaths & 001-999 & 81 & 114.99 & $0.70^{*}$ & $(0.56-0.88)$ \\
\hline \multicolumn{6}{|c|}{$\begin{array}{l}\text { SMR, standardised mortality ratio; } 95 \% \mathrm{Cl}, 95 \% \text { confidence interval. } \\
\text { †This category includes six deaths from cancer of the following sites: bone, endometrium, prostate, bladder, } \\
\text { adrenal gland, and one unknown primary site. } \\
\text { †This category includes six deaths from other causes (infectious disease, AIDS, pulmonary oedema, renal failure } \\
\text { arthritis, and one death abroad for which it was not possible to retrieve the death certificate). } \\
{ }^{*} \mathrm{p}<0.05 \text {. }\end{array}$} \\
\hline
\end{tabular}

of the International Classification of Diseases (ICD IX). Expected deaths were estimated on the basis of five year age groups, sex, and calendar year specific national mortality rates. Standardised mortality ratios (SMRs) were estimated for overall mortality and selected groups of causes, including specific cancer sites; 95\% confidence intervals (CI) were calculated based on the assumption of a Poisson distribution for deaths observed in the follow up period. Analyses were carried out separately for UC and CD and for each IBD type by sex. In the estimation of expected deaths due to cancer of the colon or rectum, the follow up period at risk was censored at the date of surgery in a subgroup of 52 patients $(5.7 \%)$ who had undergone total colectomy and/or rectum resection during the study period, as appropriate.

The same analyses were also carried out using local mortality rates in order to take into account possible local specific patterns of mortality. Only results based on national rates (which are more stable being based on much larger numbers of deaths) are shown, except for two specific results in the non-neoplastic gastrointestinal disease group.

\section{RESULTS}

Overall, 920 IBD patients (689 UC and 231 CD) were originally identified as residing in the area at any time during the period 1978-1992 and followed from enrolment until death or 31 December 2001. At the end of the study period, vital status information was not available for seven patients $(0.8 \%)$. A total of approximately 14040 person years (10 489 for UC patients and 3551 for CD patients) were available for analysis, with a median follow up of 14.8 years. Male patients numbered 525 (410 UC and 115 CD) and female patients 395 (279 UC and $116 \mathrm{CD}$ ), and provided, respectively, 8035 and 6005 person years. Mean age at first diagnosis was 41.5 years for UC patients and 37.4 years for CD patients. Overall, 118 deaths (69 in males and 49 in females) were identified in the whole cohort.

\section{UC patients}

General mortality was significantly lower (30\%) than expected in UC patients (SMR 0.70 (95\% CI $0.56-0.88)$ ) based on the observation of 81 deaths ( 53 in males and 28 in females) (table 1). This result was mostly due to a significantly reduced number of cardiovascular deaths (SMR 0.67 (95\% CI 0.45-0.95)) and to a reduction in total cancer mortality (SMR 0.71 (95\% CI 0.47-1.04)). In the latter group of causes, lung cancer mortality was strongly and significantly reduced (SMR 0.32 (95\% CI 0.07-0.95)). A non significant excess of deaths from haemolymphopoietic malignancies was observed (four cases versus 2.5 expected), with two deaths from non-Hodgkin's lymphoma. Two deaths due to cancer of the hepatobiliary system were observed versus 1.90 deaths expected. No excess for colorectal cancer mortality was evident (SMR 1.26 (95\% CI 0.34-3.24)) based on four observed deaths.

Considering non-cancer causes of death, only mortality due to gastrointestinal disease was increased, although not significantly (SMR 1.57 (95\% CI $0.78-2.81)$ ), based on 11 observed deaths. Among these 11 deceased subjects, five died from causes directly related to UC (two surgical complications, one toxic megacolon, one sigma perforation, and one intestinal infarction) while in three cases the death certificate mentioned only UC and cardiovascular insufficiency as the condition eventually leading to death; two deaths were related to complications of duodenal and gastric ulcer, respectively, and one to pancreatitis. This increased risk was more evident and reached statistical significance in the analysis carried out using local mortality rates (SMR 2.12 (95\% CI 1.05-3.80)). No other relevant differences were evident using local rates.

No remarkable differences in total and cause specific mortality emerged in the analyses carried out separately by sex.

\section{Crohn's disease patients}

The results obtained for the subcohort of CD patients are reported in table 2. For general mortality, a significant $50 \%$ increase was evident (SMR 1.51 (95\% CI 1.06-2.08)) based on 37 observed deaths (16 in males and 21 in females) and 24.55 expected. Deaths due to non-malignant gastrointestinal causes were significantly increased (SMR 4.49 (95\% CI 
Table 2 General and cause specific mortality in the follow up of a population based cohort of 231 Crohn's disease patients ( 3551 person years) by major groups of diagnostic categories (Florence IBD study 1978-2001)

\begin{tabular}{|c|c|c|c|c|c|}
\hline \multirow[b]{2}{*}{ Cause of death } & \multirow[b]{2}{*}{ ICD IX } & \multicolumn{2}{|l|}{ Deaths } & \multirow[b]{2}{*}{ SMR } & \multirow[b]{2}{*}{$95 \% \mathrm{Cl}$} \\
\hline & & $\begin{array}{l}\text { Observed } \\
\text { (n) }\end{array}$ & $\begin{array}{l}\text { Expected } \\
\text { (n) }\end{array}$ & & \\
\hline Neoplasms & $140-208$ & 17 & 8.10 & $2.10^{*}$ & $(1.22-3.36)$ \\
\hline Digestive system & $150-159$ & 5 & 2.82 & 1.77 & $(0.57-4.14)$ \\
\hline Stomach & 151 & 2 & 0.71 & 2.82 & $(0.32-10.17)$ \\
\hline Colon-rectum & $153-154$ & $\overline{1}$ & 0.71 & 1.41 & $(0.02-7.84)$ \\
\hline Respiratory system & $160-165$ & 7 & 1.98 & $3.50^{*}$ & $(1.42-7.28)$ \\
\hline Lung & 162 & 7 & 1.75 & $4.00^{*}$ & $(1.60-8.24)$ \\
\hline Other neoplasms $†$ & & 5 & 3.30 & 1.52 & $(0.49-3.54)$ \\
\hline Cardiovascular diseases & $390-459$ & 6 & 9.27 & 0.65 & $(0.24-1.41)$ \\
\hline Gastrointestinal diseases & $520-579$ & 7 & 1.56 & $4.49^{*}$ & $(1.80-9.25)$ \\
\hline Other causes $\ddagger$ & & 7 & 5.62 & 2.80 & $(0.50-2.57)$ \\
\hline All deaths & 001-999 & 37 & 24.55 & $1.51^{*}$ & $(1.06-2.08)$ \\
\hline \multicolumn{6}{|c|}{$\begin{array}{l}\text { SMR, standardised mortality ratio; } 95 \% \mathrm{Cl}, 95 \% \text { confidence interval. } \\
\text { †This category includes five deaths from cancer at other sites (breast, endometrium, prostate, brain, and myeloma) } \\
\text { †This category includes seven deaths from other causes (infectious disease, psychiatric pathology, pulmonary } \\
\text { failure, renal failure, musculoskeletal pathology, violent cause, and one ill defined cause). } \\
{ }^{*} p<0.05 \text {. }\end{array}$} \\
\hline
\end{tabular}

1.80-9.25)) based on seven cases; two of these deaths were directly related to $\mathrm{CD}$ (one intestinal infarction and one intestinal bleeding) and in two cases the death certificate mentioned only CD and cardiovascular insufficiency as the condition eventually leading to death. Three deaths were due to non-alcoholic cirrhosis. Also, total cancer mortality was significantly increased (SMR $2.10 \quad$ (95\% $\quad$ CI $1.22-3.36)$ ) (table 2), particularly lung cancer mortality (SMR 4.00 (95\% CI 1.60-8.24)). Only one death from colorectal cancer was reported ( 0.71 expected). The increased mortality for gastrointestinal disease was even more evident in the analysis carried out using local mortality rates (SMR 6.14 (95\% CI 2.46-12.65)). No other relevant differences were evident using local rates.

No remarkable differences in total and cause specific mortality emerged among CD patients according to gender.

\section{Smoking habits of deceased IBD patients}

Information on smoking habits was retrieved for 113 of 118 deceased patients $(95.76 \%)$ from available clinical records or interviews of next of kin (table 3). Smoking history at diagnosis was significantly different among UC and CD patients $(p=0.003)$. The prevalence of current smokers was higher among CD (58.33\%) than among UC (25.97\%) deceased subjects while the prevalence of never smokers was $45.46 \%$ in UC and $30.56 \%$ in CD deceased subjects. A previous history of cigarette smoking was reported by 22 UC $(28.57 \%)$ and only four CD patients $(11.11 \%)$. All seven CD patients deceased from lung cancer were current $(n=5)$ or

Table 3 Smoking habits reported at diagnosis of IBD for $113 / 118+$ deceased subjects in the Florence IBD cohort, by IBD type (Florence IBD study 1978-2001)

\begin{tabular}{lll}
\hline Smoking habit & UC (n (\%)) & CD (n (\%)) \\
\hline Current smoker & $20(25.97)$ & $21(58.33)$ \\
Former smoker & $22(28.57)$ & $4(11.11)$ \\
Never smoker & $35(45.46)$ & $11(30.56)$ \\
& & $\mathrm{p}=0.003^{*}$ \\
Total & $77(100.00)$ & $36(100.00)$ \\
\hline
\end{tabular}

IBD, inflammatory bowel disease; UC, ulcerative colitis; $C D$, Crohn's disease.

†Data on smoking habits are missing for five deceased subjects (one CD and four UC patients).

${ }^{*} p$ value from $\chi^{2}$ test ( 2 degrees of freedom). former $(n=2)$ smokers; on the other hand, among the three UC patients deceased from lung cancer, one was a never smoker at diagnosis and until death, one was a former smoker, and the other one was reported as a current smoker at diagnosis.

\section{DISCUSSION}

The results of this population based study clearly confirm the existence of two specific and divergent patterns of mortality among UC and CD patients that correlate with well known differences in smoking history between the two conditions. These differences have been documented among deceased subjects in our cohort, confirming a higher prevalence of current smokers among CD patients.

In UC patients, a significant reduction in total mortality was evident due to a cardiovascular mortality significantly lower than in the general population. Total cancer mortality was also reduced in these patients, with a $70 \%$ reduction in lung cancer mortality. In contrast, total mortality was 50\% higher in $\mathrm{CD}$ patients in comparison with the general population. This excess was related to a fivefold increase in mortality due to gastrointestinal diseases and to an increase in total cancer mortality, mostly due to a fourfold increase in lung cancer mortality.

We have previously shown that IBD incidence rates increased in this population over a 15 year period in the Florence metropolitan area $^{17}$; a capture-recapture analysis showed that our case ascertainment was accurate in comparison with other studies. ${ }^{19}$ Follow up of this large series was almost complete and no selected loss occurred. The analyses were carried out using both national and local mortality rates in order to take into account possible geographical differences in rates, but the results were very similar.

Most reports have described a low or only slightly increased mortality for UC patients. ${ }^{2-8}{ }^{10}$ In a recent study in a Danish population based cohort of 1160 UC patients with a median follow up of 19 years, total mortality was similar to the general population. ${ }^{9}$ A few Northern European studies, on the other hand, have reported moderately increased mortality. ${ }^{11-14}$

A significant excess mortality in $\mathrm{CD}$ patients has been reported in population based mortality studies. ${ }^{13-15}$

A specific pattern of smoking habits, traditionally reported as negatively associated with UC, ${ }^{20}{ }^{21}$ probably contributed to the reduced mortality for a group of smoking related causes, 
including lung cancer and cardiovascular deaths, in UC patients. A reduction in mortality for cancer of the respiratory system has also been reported in a multicentre hospital based study in a large series of Italian UC patients. ${ }^{8}$ Increased mortality for respiratory diseases in UC has been reported by others $^{69^{12} 13}$ but was associated with asthma or pneumonia more than bronchitis and emphysema. Five cancer incidence studies carried out in the UK, Denmark, Sweden, Canada, ${ }^{22-25}$ and in our Florence IBD cohort ${ }^{18}$ reported a decrease in lung cancer incidence in UC patients.

In contrast, long term treatments based on salicylates may also have contributed to reduced cardiovascular mortality. ${ }^{12}$

The smoking history of CD patients has been consistently reported as being characterised by a much higher frequency of current smokers in comparison with the general population. ${ }^{2021}{ }^{26}$ A 40\% excess mortality for lung cancer, approaching the level of statistical significance, was reported in a study on hospitalised CD patients in Denmark ${ }^{27}$ while two cancer incidence studies showed an increased risk for lung cancer. ${ }^{25}{ }^{28}$ It is noteworthy that CD patients in our study showed a fourfold excess of mortality for gastrointestinal diseases, mostly related to specific complications. Smoking has been reported to be an independent risk factor for recurrence of $\mathrm{CD}$, influencing disease activity after surgery ${ }^{29}$ and clinical relapse. ${ }^{30}{ }^{31}$ Benefits of smoking cessation on the clinical course of the disease and therapeutic needs have also been suggested by an intervention study. ${ }^{32}$

Overall no evidence of an increased mortality for large bowel cancer emerged in this series. In our analysis, we also took into account the proportion of patients who had undergone extensive colorectal surgery, censoring their observation time at that exact date, thus reducing the number of expected cases of colon and/or rectal cancer in the site specific analyses. Long term maintenance treatment has been advocated by most clinicians in the Florence area. ${ }^{33}$ A reduced risk for colorectal cancer in UC patients actively treated with anti-inflammatory drugs has been reported ${ }^{34} 35$ and also experimental data suggest that mesalazine has antiinflammatory properties and can affect the proliferation of colon epithelial cells. ${ }^{36}$ Overall, however, population based studies in the last decade have reported estimates of colorectal cancer mortality substantially lower ${ }^{12}{ }^{13}$ in comparison with earlier studies, and some studies reported no significant differences in colorectal cancer mortality among UC patients in comparison with the general population. ${ }^{29}$

An increased risk for colorectal cancer has been consistently reported in most population based cancer incidence studies in UC patients, ${ }^{623-25} 37$ with a few exceptions. ${ }^{418} \mathrm{~A}$ strong increase in the incidence of colorectal cancer has been reported in clinical series of UC patients followed by referral centres $^{22} 3839$; similar studies have also reported increased risks for both $\mathrm{CD}$ and UC patients with extensive colitis. ${ }^{40}$ In contrast, CD patients did not show an increased risk of colorectal cancer in population based incidence studies, $^{18} 262741$ with few exceptions. ${ }^{25} 42$

In conclusion, the long term follow up results of this relatively large population based series of IBD patients identified in a Mediterranean country have shown two clearly divergent mortality patterns for UC and CD, particularly evident for lung cancer, with a $70 \%$ reduction and a fourfold increase in risk, respectively.

Smoking habits appear to contribute significantly to the increased mortality observed in CD. Considering the other negative effects on the clinical course of the disease, family doctors and gastroenterologists following CD patients should consider cessation of cigarette smoking a specific priority for these patients, often young and with a long life expectancy. Free participation in structured programmes for smoking cessation should be offered, with the aim of reducing smoking related excess mortality.

\section{ACKNOWLEDGEMENTS}

The authors acknowledge the support of other members of the Florence IBD Study Group (particularly Franco Pacini, Monica Milla, and Gabriella Nesi), the cooperation of the local association of IBD patients (AMICI), the Regional Mortality Registry (RMR-CSPO, Florence), and Vanessa Visentin for editorial assistance.

The study was supported by Regione Toscana, Florence, Italy.

\section{Authors' affiliations}

G Masala, M Ceroti, C Saieva, I Zanna, D Palli, Molecular and Nutritional Epidemiology Unit, CSPO-Scientific Institute of Tuscany, Florence, Italy

S Bagnoli, G Trallori, Department of Gastroenterology, AO Careggi, Florence, Italy

G d'Albasio, Department of Gastroenterology, AO Careggi, Florence, Italy, and Regional IBD Referral Centre, Florence, Italy

\section{REFERENCES}

1 Podolski DK. Inflammatory bowel disease. N Engl J Med 2002;347:417-29.

2 Palli D, Trallori G, Saieva C, et al. General and cancer specific mortality of a population based cohort of patients with inflammatory bowel disease: the Florence Study. Gut 1998:42:175-9.

3 Stonnington $\mathrm{CM}$, Phillips SF, Zinsmeister AR, et al. Prognosis of chronic ulcerative colitis in a community. Gut 1987;28:1961-6.

4 Langholz E, Munkholm P, Davidsen M, et al. Colorectal cancer risk and mortality in patients with ulcerative colitis. Gastroenterology 1992; 103:1444-51.

5 Probert CS, Jayanthi V, Wicks AC, et al. Mortality in patients with ulcerative colitis in Leicestershire, 1972-1989. An epidemiological study. Dig Dis Sci 1993;38:538-41.

6 Stewenius J, Adnerhill I, Anderson $\mathrm{H}$, et al. Incidence of colorectal cancer and all cause mortality in non-selected patients with ulcerative colitis and indeterminate colitis in Malmo, Sweden. Int J Colorectal Dis 1995;10:1 17-22.

7 Davoli M, Prantera C, Berto E, et al. Mortality among patients with ulcerative colitis: Rome 1970-1989. Eu J Epidemiol 1997;13:189-94.

8 Viscido A, Bagnardi V, Sturniolo GC, et al. Survival and causes of death in Italian patients with ulcerative colitis. A GISC nation-wide study. Digest Liver Dis 2001;33:686-92.

9 Winther KV, Jess T, Langholz E, et al. Survival and cause-specific mortality in ulcerative colitis: follow-up of a population-based cohort in Copenhagen County. Gastroenterology 2003;125:1576-82.

10 Farrokhyar F, Swarbrick ET, Grace RH, et al. Low mortality in ulcerative colitis and Crohn's disease in three regional centers in England. Am J Gastroenterol 2001;96:501-7.

11 Brostrom O, Monsen U, Nordenwall B, et al. Prognosis and mortality of ulcerative colitis in Stockholm county, 1955-1979. Scand J Gastroenterol 1987;22:907-13.

12 Ekbom A, Helmick CG, Zack M, et al. Survival and cause of death in patients with inflammatory bowel disease: a population based-study. Gastroenterology 1992;103:954-60.

13 Persson PG, Bernell O, Leijonmarck C-E, et al. Survival and cause-specific mortality in inflammatory bowel disease: a population based cohort study. Gastroenterology 1996;110:1339-45.

14 Card T, Hubbard R, Logan RFA. Mortality in inflammatory bowel disease: a population-based cohort study. Gastroenterology 2003;125:1583-90.

15 Jess T, Whinter KV, Munkholm P, et al. Mortality and causes of death in Crohn's disease: follow-up of a population-based cohort in Copenhagen County, Denmark. Gastroenterology 2002;122:1808-14.

16 Cottone M, Magliocco A, Rosselli M, et al. Mortality in patients with Crohn's disease. Scand J Gastroenterol 1996;31:372-5.

17 Trallori G, Palli D, Saieva C, et al. A population-based study of inflammatory bowel disease in Florence over 15 years (1978-92). Scand J Gastroenterol 1996;31:892-9.

18 Palli D, Trallori G, Bagnoli S, et al. Hodgkin's disease risk is increased in ulcerative colitis patients. Gastroenterology 2000;119:647-53.

19 Palli D, Masala G, Saieva C. Population-based studies of IBD incidence in Italy and capture-recapture methods. Int J Epidemiol 1997;26:904-6.

20 Franceschi S, Panza E, La Vecchia C, et al. Nonspecific inflammatory bowel disease and smoking. Am J Epidemiol 1987;125:445-52.

21 Tobin MV, Logan RFA, Langman MJS, et al. Cigarette smoking and inflammatory bowel disease. Gastroenterology 1987;93:316-21.

22 Prior P, Gyde SN, Macartney JC, et al. Cancer morbidity in ulcerative colitis. Gut 1982;23:490-7.

23 Mellemkjaer L, Olsen JH, Frisch $M$, et al. Cancer in patients with ulcerative colitis. Int J Cancer 1995;60:330-3

24 Karlen P, Lofberg R, Brostrom O, et al. Increased risk of cancer in ulcerative colitis: a population-based cohort study. Am J Gastroenterol 1999;94:1047-52

25 Bernstein CN, Blanchard JF, Kliewer E, et al. Cancer risk in patients with inflammatory bowel disease. Cancer 2001;91:854-62. 
26 Thomas GAO, Rhodes J, Green JT. Inflammatory bowel disease and smoking A review. Am J Gastroenterol 1998;93:144-9.

27 Mellemkjaer L, Johansen C, Gridley G, et al. Crohn's disease and cancer risk (Denmark). Cancer Causes Control 2000;11:145-50.

28 Persson PG, Karlen P, Bernell O, et al. Crohn's disease and cancer: a population based cohort study. Gastroenterology 1994;107:1675-9.

29 Cottone $M$, Rosselli $M$, Orlando A, et al. Smoking habits and recurrence in Crohn's disease. Gastroenterology 1994;106:643-8.

30 Cosnes J, Carbonnel F, Carrat F, et al. Effects of current and former cigarette smoking on the clinical course of Crohn's disease. Aliment Pharmacol Ther 1999; 13:1403-11.

31 Timmer A, Sutherland LR, Martin F. Canadian Mesalamine for Remission of Crohn's Disease Study Group. Oral contraceptive use and smoking are risk factors for relapse in Crohn's disease. Gastroenterology 1998; 114:1143-50

32 Cosnes J, Beaugerie L, Carbonnel F, et al. Smoking cessation and the course of Crohn's disease: an intervention study. Gastroenterology 2001;120:1093-9.

33 D'Albasio G, Pacini F, Camarri E, et al. Combined therapy with 5aminosalicylic acid tablets and enemas for maintaining remission in ulcerative colitis: a randomized double-blind study. Am J Gastroenterol 1997;92:1143-7.
34 Eaden J, Abrams K, Ekbom A, et al. Colorectal cancer prevention in ulcerative colitis: a case-control study. Aliment Pharmacol Ther 2000;14:145-53.

35 Pinczowski D, Ekbom A, Baron J, et al. Risk factors for colorectal cancer in patients with ulcerative colitis: a case-control study. Gastroenterology 1994;107:117-20.

36 Reinacher-Schick A, Schoeneck A, Graeven U, et al. Mesalazine causes a mitotic arrest and induces caspase-dependent apoptosis in colon carcinoma cells. Carcinogenesis 2003;24:443-51.

37 Ekbom A, Helmick CG, Zack $M$, et al. Ulcerative colitis and colorectal cancer. A population based study. N Engl J Med 1990;323:1228-33.

38 Gyde SN, Prior P, Allan RN, et al. Colorectal cancer in ulcerative colitis: a cohort study of primary referrals from three centres. Gut 1988;29:206-17.

39 Kvist N, Jacobsen O, Kvist HK, et al. Malignancy in ulcerative colitis. Scand J Gastroenterol 1989:24:497-506.

40 Gillen CD, Walmsley RS, Prior P, et al. Ulcerative colitis and Crohn's disease: a comparison of the colorectal cancer risk in extensive colitis. Gut 1994;35:1590-2.

41 Munkholm P, Langholz E, Davidsen M, et al. Intestinal cancer risk and mortality in patients with Crohn's disease. Gastroenterology 1993;105:1716-23.

42 Ekbom A, Helmick C, Zack M, et al. Increased risk of large-bowel cancer in Crohn's disease with colonic involvement. Lancet 1990;336:357-9. 